\title{
Comparative Study of Preoperative Fine Needle Aspiration Cytology And Ultrasonography with Postoperative Histopathology of Thyroid Nodule
}

\author{
Dr. Utkrisht Kant ${ }^{1}$,Dr. Vinay Pratap ${ }^{2}$,Dr. Anil Kumar Kamal ${ }^{3}$. \\ ${ }^{1}$ Senior Resident, Department of General Surgery, Rajendra Institute of Medical Sciences, Ranchi. \\ ${ }^{2}$ Associate Professor, Department of General Surgery, Rajendra Institute of Medical Sciences, Ranchi. \\ ${ }^{3}$ Associate Professor, Department of General Surgery, Rajendra Institute of Medical Sciences, Ranchi
}

\begin{abstract}
:
Introduction: About 70\% of discrete thyroid swelling is clinically "isolated" and 30\% are dominant. In India the prevalence of a palpable thyroid nodule in the community is about $12.2 \%$

Material and Method: A total of 100 patients of thyroid swelling entered the study. This is a prospective comparative study of patients admitted for solitary thyroid nodule at Rajendra Institute of Medical sciences (RIMS).

Results: The sensitivity and specificity of FNAC was $85.71 \%$ and $100 \%$ respectively. All malignant lesions on FNAC were confirmed by histopathology indicating its excellence. Therefore FNAC helps in planning the correct management and avoids second surgery and the sensitivity and specificity of USG was $78.94 \%$ and $85.33 \%$ respectively. Therefore use of ultrasound along with FNAC will improve the diagnostic accuracy to higher level and help in better management
\end{abstract}

Conclusion: Combination of both FNAC and Ultrasound will give optimal results and avoid mismanagement.

Keywords: FNAC, USG, HPE, Thyroid Nodule.

\section{Introduction}

The term 'thyroid nodule' refers to distinct lesion in the thyroid gland that is palpably or radiologically distinct from thyroid parenchyma (discrete thyroid swelling). A discrete swelling in an otherwise impalpable gland is termed as isolated or solitary and discrete swelling in a gland with clinical evidence of abnormality elsewhere in thyroid is dominant nodule.About $70 \%$ of discrete thyroid swelling is clinically "isolated" and $30 \%$ are dominant. ${ }^{1}$ In India the prevalence of a palpable thyroid nodule in the community is about $12.2 \%{ }^{2}$.However, thyroid cancer is quite rare, it is the most common endocrine malignancy and the incidence is 8.7 per 100000 people per year in US, though this seems to be increasing over the years ${ }^{3}$. It is therefore crucial to have a clear diagnostic approach to ensure patients, presenting with thyroid nodules, are managed appropriately and are not over or under-treated. Present study is to evaluate FNAC and USG as a diagnostic method in solitary thyroid nodule and to plan surgery accordingly.

The name thyroid is derived from the Greek description of a shield shaped gland in the anterior aspect of the neck ( thyroides) ${ }^{4}$.Goiters were known in China in 2700 B.C, but it was the Italians of the Renaissance period who first recognized the normal thyroid gland.The first credible account of thyroid surgery was given in 1770 by Roger Frugardi of salerno in the Bamberg manuscript. The first well documented thyrodectomy was undertaken in paris in 1791, pierre joseph de sault during the terror of French revolution. In the late 19th century two surgeons revolutionized the treatment of thyroid disease - Theodor Billroth and Emil theodor kocher. As a result of pioneering developments in the understanding thyroid physiology, kocher received the Noble prize in 1909. Payer recorded the first transplantation of thyroid in 1906. He transplanted a portion of the thyroid from a woman in to the spleen of her myxedemic daughter ${ }^{5}$.

Scandinavian workers first introduced the fine needle aspiration. It eventually gained acceptance and was endorsed by the American thyroid association. This technique is one of the standard methods in the evaluation of thyroid nodules. FNA decreases the overall cost of care by approximately $25 \%$, mainly by eliminating unnecessary surgeries and limiting the use of frozen section intra operatively and increases diagnostic yield of cancers at thyroidectomy (AACE,2006) ${ }^{6}$. It should be correlated with clinical findings and other investigations. The advantage being it is a simple office procedure, can done without any anaesthesia, and is cost effective. The technique is relatively painless and produces a speedy result. Its better efficacy avoids the need for frozen section study $(1990)^{7}$. American Association of Clinical Endocrinologists (AACE, 2006$)^{8}$ recommends ultrasound (USG)-guided fine-needle aspiration (FNA), universally for all thyroid nodules that are $\geq 10 \mathrm{~mm}$ in diameter in euthyroid subjects ${ }^{6}$. It is reported by Goudy SL et al (2005) ${ }^{9}$ that 9 to $47 \%$ of palpation-guided and 4 to $21 \%$ of ultrasound guided FNA smears are inadequate. 
As reported by Frates et al $(2006)^{10}$, the more cystic a nodule is, the lower the likelihood of cancer. Hypoechoic nodules had a higher rate of malignancy than isoechoic or hyperechoic nodules. The presence of coarse or rim calcifications increased the likelihood of cancer almost 2-fold, when compared with the malignancy rate for nodules without calcification. Punctate microcalcifications increased the likelihood almost 3-fold. Well-defined or poorly defined nodule margins were not significantly associated with presence of thyroid cancer. Thyroid ultrasound has become the first line imaging modality for evaluation of thyroid gland, and has largely supplanted scintigraphy for thyroid evaluation due to excellent visualization of thyroid parenchyma, its high sensitivity in detection of small nodules, calcification, septations, and cyst formation, as well as image guidance for needle-aspiration biopsies. USG findings are nonspecific and play a very limited role in the diagnosis of diffuse thyroid diseases. The main application of USG in such circumstances is identification of co-existent nodular lesions and monitoring structural changes and vascularity of the gland in response to medical treatment. An USG is a safe, non invasive, non radioactive test that should be ordered judiciously.

Generally, most thyroid nodules are benign and can be classified as ${ }^{11}$ adenomas, colloid nodules, cysts, infectious nodules, lymphocytic or granulomatous nodules, congenital abnormalities or hyperplasia. Malignant thyroid nodule ${ }^{12}$ (AACE ,2010) include Papillary carcinoma, Follicular carcinoma, Hürthle cell carcinoma, Poorly differentiated carcinoma, Medullary carcinoma, Anaplastic carcinoma Primary thyroid lymphoma Sarcoma, teratoma, and Metastatic tumors.

\section{Materials And Methodology}

This is a prospective comparative study of patients admitted for solitary thyroid nodule at Rajendra Institute of Medical sciences (RIMS).

Inclusion Criteria: All patients who admitted with solitary thyroid nodule with age between 11 - 70years.

\section{Exclusion Criteria:}

1. Patients with thyroid swellings which are not nodular or multinodular or with dominant nodule.

2. Patients unfit for surgery

3. Patients who fail to give proper history and those without next of kin to consent for the study will be excluded from the study.

All patients are examined clinically after taking a detailed history. Then, they are investigated with FNAC and USG of the thyroid. Then, all the patients are subjected to surgery and histopathological examination (HPE) of the specimen obtained. Finally, the histopathology reports will be compared with the findings of FNAC and USG in order to evaluate their sensitivity and specificity by statistical methods.

\section{Results}

Statistical Analysis: The data was analyzed by using SPSS 20 software. The data is presented in percentages, rates and ratios. Chi square test was used to find the association between attributes.

Table - I: Age and sex distribution

\begin{tabular}{|c|c|c|c|}
\hline Age ( years) & Male (30) & Female (70) & Total (100) \\
\hline $11-20$ & 1 & 8 & 9 \\
\hline $21-30$ & 5 & 23 & 28 \\
\hline $31-40$ & 10 & 28 & 38 \\
\hline $41-50$ & 9 & 6 & 15 \\
\hline $51-60$ & 4 & 4 & 8 \\
\hline $61-70$ & 1 & 1 & 2 \\
\hline
\end{tabular}

Commonest age group of presentation was 31-40 years, mean age was 35.5 years. Ratio of female was $70 \%$. M: F ratio -1: 2.33

Table - II: FNAC report

\begin{tabular}{|c|c|c|}
\hline FNAC lesion & No. of Cases & Percentage \\
\hline Colloid nodule & 25 & 25 \\
\hline Nodular goiter & 16 & 16 \\
\hline Benign cystic lesion & 13 & 13 \\
\hline Chronic lymphocytic thyroiditis & 4 & 4 \\
\hline Follicular neoplasia & 18 & 18 \\
\hline Papillary carcinoma & 8 & 8 \\
\hline Medullary carcinoma & 3 & 3 \\
\hline Anaplastic carcinoma & 1 & 6 \\
\hline Suspicious of malignant papillary neoplasm & 6 & 6 \\
\hline Inadequate aspirate & 6 & \\
\hline
\end{tabular}


Comparative Study Of Preoperative Fine Needle Aspiration Cytology And.....

On FNAC $58 \%$ of nodules were benign and $12 \%$ were malignant. $43.10 \%$ (25) of benign lesion were colloid nodule and $6.90 \%$ (4) were lymphocytic thyroiditis.

Table - III: USG report

\begin{tabular}{|c|c|c|}
\hline USG Report & No. of Cases & Percentage \\
\hline Cystic & 11 & 11 \\
\hline Hyperechoic nodule & 43 & 43 \\
\hline MNG & 14 & 14 \\
\hline Mixed hypoechoic & 26 & 26 \\
\hline Suspicious & 6 & 6 \\
\hline
\end{tabular}

On USG $68 \%$ of nodules had features suggestive of benign nodule and $26 \%$ were malignant.

Table - IV: HPE report

\begin{tabular}{|c|c|c|}
\hline HPE Report & No. of Cases & Percentage \\
\hline Benign follicular adenoma & 31 & 31 \\
\hline Colloid nodule & 24 & 24 \\
\hline Benign cyst & 10 & 2 \\
\hline Hyperplastic nodule & 02 & 8 \\
\hline MNG & 08 & 4 \\
\hline Chronic lymphocytic thyroiditis & 04 & 4 \\
\hline Follicular carcinoma & 04 & 13 \\
\hline Papillary carcinoma & 13 & 3 \\
\hline Medullary carcinoma & 03 & 1 \\
\hline Anaplastic carcinoma & 01 & \\
\hline
\end{tabular}

$79 \%$ of clinically diagnosed solitary nodules were benign and $21 \%$ of nodules were malignant. So incidence of malignancy in clinically diagnosed solitary thyroid nodule is $21 \%$ (100\% specific, as on FNAC report). Most common benign nodule was benign follicular adenoma (31\%), followed by colloid nodule and benign cyst ( $24 \%$ and $10 \%$ respectively).

Table - V: Correlation of FNAC lesions with HPE

\begin{tabular}{|l|l|c|}
\hline \multicolumn{1}{|c|}{ FNAC lesions } & Histopathological diagnosis & $\mathrm{n}-100$ \\
\hline Inadequate aspirate ( 06) & Benign Follicular adenoma & 04 \\
& Colloid nodule & 02 \\
\hline & Benign follicular Adenoma & 11 \\
Colloid nodule ( 25) & Colloid nodule & 21 \\
Nodular goiter (16) & MNG & 08 \\
Benign cystic lesion (13) & Benign cyst & 10 \\
Chronic lymphocytic thyroiditis ( 04) & Hyperplastic nodule & 02 \\
& Lymphocytic thyroiditis & 04 \\
\hline Follicular neoplasia (18) & Papillary carcinoma & 02 \\
\hline suspicious of malignant papillary carcinoma & Benign Follicular adenoma & 14 \\
(06) & Follicular carcinoma & 04 \\
\hline Papillary carcinoma (08) & Colloid nodule & 02 \\
Medullary carcinoma (03) & Papillary carcinoma & 01 \\
Anaplastic carcinoma( 01) & Papillary carcinoma & 03 \\
\hline
\end{tabular}

All inadequate FNAC were benign on HPE. Out of 58 benign on FNAC only $2(3.44 \%)$ turn out malignant on HPE. Out of 18 follicular Neoplasia 4 turn out malignant [follicular carcinoma] on HPE, so incidence of malignancy was $22.22 \%$ in this group. 3 out of 6 report of suspicious lesion turn out malignant, so Incidence of malignancy is 50\%. All malignant aspirate were malignant too in HPE (100\% specific).

Table - VI: Correlation of Ultrasonography with Histopathology

\begin{tabular}{|l|l|c|}
\hline \multicolumn{1}{|c|}{ USG Report } & \multicolumn{1}{|c|}{ Histopathological diagnosis } & $\mathrm{n}-100$ \\
\hline & Benign follicular adenoma & 27 \\
Cystic (11) & Colloid nodule & 21 \\
Hyperechoic nodule (43) & Benign cyst & 06 \\
MNG(14) & Hyperplastic nodule & 02 \\
& MNG & 08 \\
& Papillary carcinoma & 04 \\
\hline \multirow{3}{*}{ Suspicious (06) } & Benign cyst & 02 \\
& MNG & 02 \\
\hline Mixed echogenic & Papillary carcinoma & 02 \\
\hline
\end{tabular}


Comparative Study Of Preoperative Fine Needle Aspiration Cytology And.....

\begin{tabular}{|l|l|c|}
\hline And & Follicular carcinoma & 04 \\
hypoechoic nodule (26) & Medullary carcinoma & 03 \\
& Anaplastic carcinoma & 01 \\
& Benign follicular adenoma & 04 \\
& MNG & 02 \\
& Colloid nodule & 03 \\
& Benign cyst & 02 \\
\hline
\end{tabular}

$4(5.88 \%)$ out of 68 benign Ultrasonography lesion turnout malignant on HPE. Incidence of malignancy in suspicious lesion is $33.33 \%$ (2/6) In total 26 malignant lesion on USG only 15 (57.69\%) turn out malignant rest $11(42.30 \%)$ were benign.

\section{Discussion}

Thyroid nodules are a common problem. They are found in 4-8\% of adults by population and $16-17 \%$ when ultrasound detection is used. In autopsy studies, they have a prevalence of approximately $50 \%$. The prevalence of thyroid nodules increases with age and women have a high prevalence than men. The natural history of benign nodules is unclear, but most palpable nodules reduce in size, with up to $38 \%$ disappearing altogether. Sometimes this clinically palpated solitary thyroid nodule may be part of a diffuse multinodular disease group ${ }^{13}$.

This forms the most important indication for the use of ultrasound in thyroid pathologies i.e. to prove beyond doubt the presence of a solitary nodule. Solitary nodules presented a higher but not significantly risk of cancer as opposed to lesions embedded in multinodular goiters. Available data suggest that approximately of these solitary nodules $5 \%$ are toxic, $10 \%$ are warm and $85 \%$ are cold ${ }^{14}$.

A twenty year experience of thyroid cancers between 1953 and 1973 was reviewed. According to this study by D J Campell et al ${ }^{15}$ only 8 out of 293 cases of solitary thyroid nodules were malignant, an incidence of only $2.7 \%$. In one series of 200 patients of solitary thyroid disease the incidence of malignancy was in only 8 cases and all of these 8 were solid lesions on ultrasound .In one study of 72 patients of solitary nodules by Brander A et al, only one third of the clinically solitary- nodules proved to be solitary by ultrasound examination. Of 77 separate nodules 43 escaped detection on clinical examination In the study of Jones A J et $\mathrm{al}^{16}$ the sensitivity, specificity and positive predictive value of FNAC, radioisotope scan and ultrasound was evaluated for thyroid cancer in solitary nodules. For FNAC it was 92\%, 85\% and $41 \%$ respectively. For ultrasound it was $75 \%, 61.1 \%$ and $19 \%$ while for radioisotope scanning it was $82 \%$; $34 \%$ and $11 \%$ respectively. The combined result of ultrasound and radionuclide scan was $82 \%, 34 \%$ and $11 \%$. In one study of solitary nodules by Serga A et al only $64.3 \%$ of the carcinomas exhibited the typical malignant pattern on ultrasonography and in $21.4 \%$. of the carcinomas a homogenous nodule with a clear margin was observed which was often observed in benign nodules also.

The overall sensitivity in our series was $85.71 \% \& 96.55 \%$, while the specificity was $100 \% \& 85.71 \%$ for both malignant and benign lesions which is comparable to study done by kim et al . FNAC has certain limitations because of suspicious diagnosis. In present series out of $6(6 \%)$ suspicious lesion on FNAC , 3 were found to be malignant on final HPE report so incidence of malignancy in this group is $50 \%$. Due to high level of malignancy, surgery like total thyroidectomy is justifiable on basis of FNAB report . The overall incidence of malignancy in solitary thyroid nodules varies from $10 \%-30 \%$ according to various studies. In our study, the overall incidence of malignancy in solitary nodule was $18 \%$.

Watter et $\mathrm{al}^{17}$, interpreted an USG report as suggestive of malignancy if the nodule was solid or of a mixed solid-cystic variety and a hypoechoic and nonhaloed lesion. They emphasized that the USG has added advantage of allowing the whole gland to be examined rather than the dominant nodule but was limited by the fact that no features were Pathognomic for malignancy, so that it should be regarded as complementary rather than an alternative investigation to FNAC in the management of solitary thyroid nodule. It has been a consistent observation according to published literature, that the risk of thyroid cancer is less with multiple nodules than with the solitary nodules. High resolution real-time USG is far better than clinical examination in detecting thyroid nodularity. Watter et $\mathrm{al}^{17}$ have shown that the prevalence of multinodularity in clinically solitary thyroid nodules is between $20 \%$ and $40 \%$, and it has been observed that for a thyroid nodule to be detected by palpation, it must be at least $1 \mathrm{~cm}$ in diameter, while USG detects nodules as small as $3 \mathrm{~mm}$ in diameter. In present series incidence of multinodularity in clinically dignosed solitary nodule is $17 \%$.

\section{Conclusion}

The ideal test should have a sensitivity and specificity of $100 \%$. The closest method to ideal test is, thus, FNAC which has high sensitivity and specificity. However, a combination of both FNAC and Ultrasound will give optimal results and avoid mismanagement. 


\section{References}

[1]. Yeung MJ, Serpell JW. Management of the solitary thyroid nodule. Oncologist. 2008;13:105-12.]

[2]. Usha Menon V, Sundaram KR, Unnikrishnan AG, Jayakumar RV, Nair V, Kumar H. High prevalence of undetected thyroid disorders in an iodine sufficient adult south Indian population. J Indian Med Assoc.2009; 107:72-7.]

[3]. Davies L, Welch HG. Increasing Incidence of Thyroid Cancer in the United States, 1973-2002. JAMA.2006; 295:2164-7. ]

[4]. Jhon B Hanks, Thyroid. Sabiston Textbook of surgery: the biological basis of Modern Surgical Practice Vol 1, 18th. Saunder's Elsevier publishers; 2004: 947-983.

[5]. Gregory P Saddler, Orlo H Clarke, Jon A, Van Heerder. Schwartz- Principles of Surgery, 7th edition. Mcgraw hill; 1999:36: 16611711 .

[6]. American Association of Clinical Endocrinologists and medical guidelines for clinical practice for the diagnosis and management of thyroid nodules Endocr Pract 2006, 12:63-102.

[7]. Hooper M, Thyroid, Jamieson and Kay's: Textbook of Surgical Physiology. 4th edition; Churchill Livingstone; 1990:7:85-107.

[8]. Bouvet M Field Man J. Surgical management of the thyroid nodule: laryngoscope 1992; 102: 1353-56.

[9]. Goudy SL, Flynn MB: Diagnostic accuracy of palpation-guided and imageguided fine-needle aspiration biopsy of the thyroid. Ear Nose Throat J 2005, 84:371-374.

[10]. Frates MC, Benson CB, Doubilet M, Kunrenter E, Contreras M, Cibas E, et al. Prevalence and distribution of carcinoma in patients with solitary and multiple thyroid nodules on sonography J Clin Endocr \& Metab. 2006; 91:3411-17.

[11]. Daniel J Kelley, MD; Chief Editor: Arlen D Meyers, MD, MBA, Evaluation of Solitary Thyroid Nodule Medscape , july $14,2015$.

[12]. American Association of Clinical Endocrinologists and medical guidelines for clinical practice for the diagnosis and management of thyroid nodules: AACE/AME/ETA Thyroid Nodule Guidelines, Endocr Pract. 2010; 16 (Suppl 1); 1-43.

[13]. Brkljaic B, Cuk V, Tomic H. Ultrasonic evaluation of benign and malignant nodules in ecographically thyroid nodules. J Clin Ultrasound 2000; 22: 71-6.

[14]. Enrico P, Rinaldo, et al. Management of Solitary nodule thyroid, Journal of Clin Endocrinol and Metab 2002 ; 87: 1941 -46.

[15]. Campell D J. Thyroid cancer 20 years experience in a general hospital. Br J Sur 1980; 62: 207-214.

[16]. Jones A J. et al. Comparision of Fine Needle Aspiration, USG and Radionucleotide Scan in management of thyroid nodules. Post Grad Med J. 1990 66: 914-17.

[17]. Watters AK, Ahiya AT, et al. Role of USG in the management of thyroid nodule.Am J Surg 1998; 164:654-57. 